Portland State University

PDXScholar

4-1-1972

\title{
New Thin-Film Tunnel Triode Using Amorphous Semiconductors
}

\author{
Pavel Smejtek \\ Portland State University \\ R. F. Shaw \\ H. Fritzsche \\ M. Silver \\ S. Holmberg
}

See next page for additional authors

Follow this and additional works at: https://pdxscholar.library.pdx.edu/phy_fac

Part of the Physics Commons

Let us know how access to this document benefits you.

\section{Citation Details}

Pavel, S., Shaw, R., Fritzsche, H., Silver, M., Holmberg, S., \& Ovshinsky, S., New Thin-Film Tunnel Triode Using Amorphous Semiconductors. Appl. Phys. Lett. 20, 241 (1972).

This Article is brought to you for free and open access. It has been accepted for inclusion in Physics Faculty Publications and Presentations by an authorized administrator of PDXScholar. Please contact us if we can make this document more accessible: pdxscholar@pdx.edu. 


\section{Authors}

Pavel Smejtek, R. F. Shaw, H. Fritzsche, M. Silver, S. Holmberg, and S. R. Ovshinsky 


\title{
New Thin-Film Tunnel Triode Using Amorphous Semiconductors
}

\author{
R. F. Shaw, ${ }^{*}$ H. Fritzsche, ${ }^{\dagger}$ M. Silver, ${ }^{\ddagger}$ P. Smejtek, ${ }^{\ddagger}$ S. Holmberg, and S. R. Ovshinsky \\ Energy Conversion Devices, Troy, Michigan 48084 \\ (Received 2 December 1971)
}

\begin{abstract}
A new thin-film tunnel triode is discussed which uses a $p$-type amorphous film to achieve amplification of injected current from a tunnel cathode. It is not only the basis for a new semiconductor device but also suggests a novel method for measuring electrical properties of semiconductors.
\end{abstract}

A tunnel triode was fabricated using $\mathrm{Al}_{2} \mathrm{O}_{3}$ dielectric to form the hot-electron tunnel cathode and an amorphous film of $\mathrm{As}_{34} \mathrm{Te}_{28} \mathrm{Ge}_{16} \mathrm{~S}_{21} \mathrm{Se}_{1}$ to separate the base and collector. The structure of the device is shown in Fig. 1. The electrodes were all aluminum. A 2000- $\AA$ emitter electrode was evaporated onto a glass substrate and anodized to form an $\mathrm{Al}_{2} \mathrm{O}_{3}$ layer $125 \AA$ thick as described by Onn and Silver. ${ }^{1}$ This was then coated with a $125-\AA$ Al layer to form the base electrode followed by a $1500-\AA$ sputtered layer of the amorphous material over which was subsequently deposited a 2000 - $\AA$ collector electrode.

The vacuum emission characteristics of the uncoated tunnel cathodes were similar to those prepared by Onn and Silver. ${ }^{1}$ The thick $\mathrm{Al}_{2} \mathrm{O}_{3}$ layer permitted operation at applied voltages in excess of the $\mathrm{Al}$ work function, thus permitting the tunneling carriers to escape the electrode surface and be emitted as hot electrons. The forward-current transfer ratio $\alpha$ for vacuum emission was on the order of $10^{-4}$.

The triodes were first made with neutral contacts to the amorphous layer, i.e., the conduction was bulk limited with a characteristic activation energy for conduction of $0.58 \mathrm{eV}$ and a room-temperature resistivity of $10^{8}$ $\Omega \mathrm{cm}$. With neutral contacts to the amorphous layer, low-temperature operation was necessitated as the Ohmic current at low collector-base voltages dominated effects due to injection from the tunnel cathode.

Operation at $77^{\circ} \mathrm{K}$ with and without a collector field showed the injected hot electrons thermalized and formed an equilibrium space charge in the amorphous layer adjacent to the base electrode causing further injected electrons to be accelerated back into the base electrode. An increase in the emitter-base current resulting in an increase in injected current caused a momentary increase in the short-circuit collector current which decayed back to zero as the space charge equilibrated. Termination of the emitter-base current caused a large reverse current which delayed back to zero with a $22-\mathrm{sec}$ time constant at $77^{\circ} \mathrm{K}$. The magni-

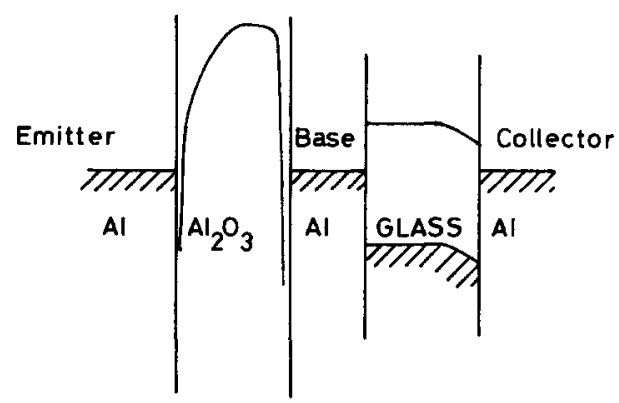

FIG. 1. Band diagram of tunnel triode. tude of the reverse current was proportional to the injection level prior to its cessation.

In order to obtain room-temperature operation, a blocking contact was made to the amorphous layer. This was accomplished by exposing the amorphous layer to a $50 \%$ relative humidity atmosphere prior to the collection electrode deposition. Photovoltage and capacitance as a function of bias voltage indicated the presence of an accumulation layer resulting in a barrier of $0.4 \mathrm{eV}$. Current-voltage measurements on the collector-film-base sandwich confirmed this value and showed the conductance to be electrode limited with an increase in resistance of $5 \times 10^{3}$.

Measured values of the short-circuit collector current with forward and reverse emitter-base currents are shown in Fig. 2. The values of $\alpha$ at zero collection bias vary from device to device but are in the range $10^{-2}$ $10^{-1}$.

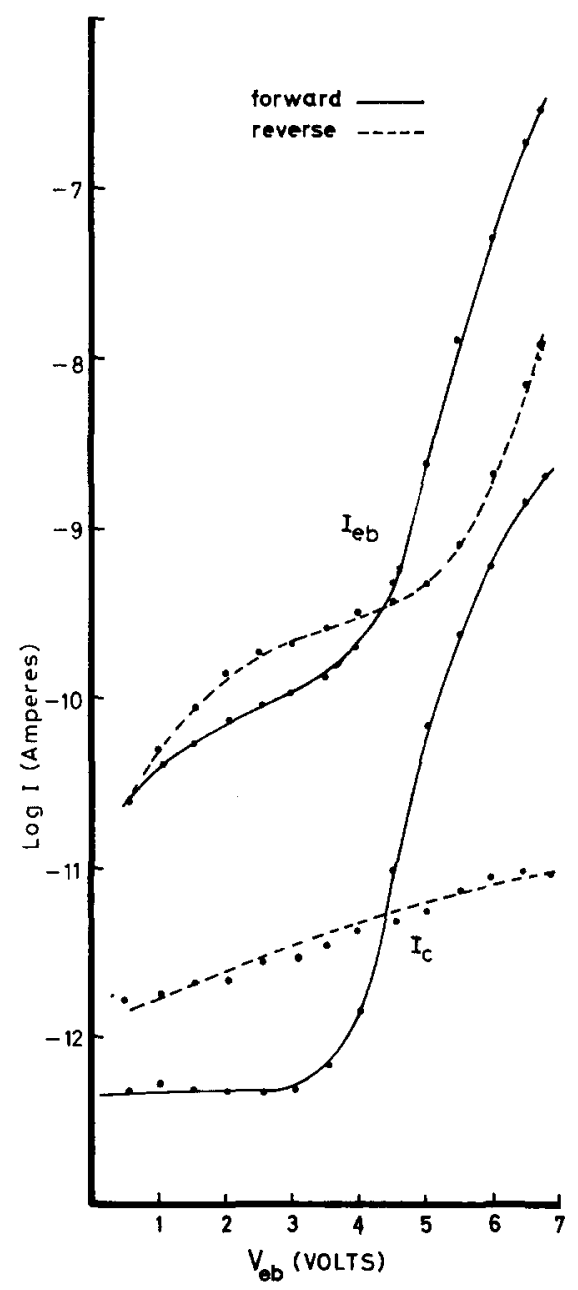

FIG. 2. Short-circuit collector current and base current as a function of forward and reverse emitter bias. 


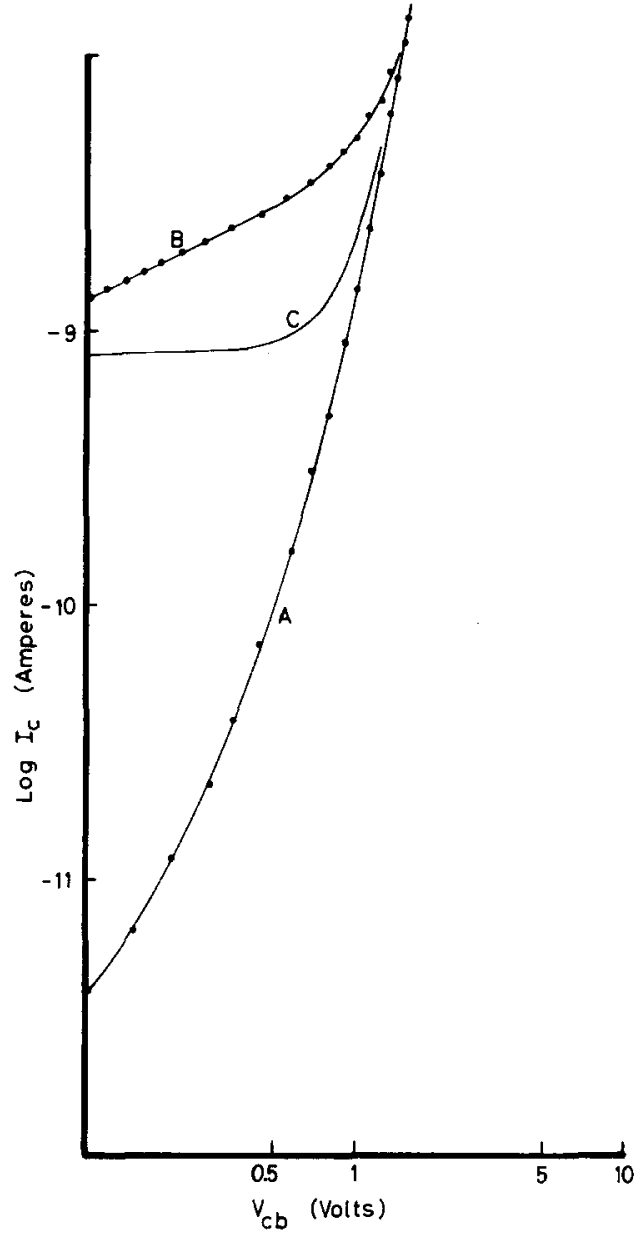

FIG. 3. Collector current as a function of collector bias with and without injection.

The lack of injection with the reverse emitter-base currents is contrary to the findings of Delord, ${ }^{2}$ who suggested that electrons could be photoemitted by luminescence in the oxide layer. The higher values of $\alpha$ result from the lowering of the effective work function by the electron affinity of the amorphous layer.

Prior investigations of tunnel-triode structures by $\mathrm{Mead}^{3}$ and others $\mathrm{s}^{4,5}$ involved the injection of majority carriers. In this structure the injected electrons are minority carriers: The material is $p$ type by thermopower measurements. The injection of minority carriers gives rise to the possibility of gain.

If charge neutrality overides recombination, the injection and thermalization of hot electrons results in an increase in the conduction-band population above the mobility edge. If the Fermi level is pinned, then an equal increase in the valence-band hole population would result.

Excepting deep trapping and recombination through deep sites, the electron current would be

$$
I_{e}=e F \tau_{e} / T_{e}
$$

and for hole current

$$
I_{h}=e F \tau_{h} / T_{h},
$$

where $\tau$ is the free-carrier lifetime, $F$ is the genera- tion rate, i.e., the injection current, and $T$ is the transit time. If, as assumed, the generation rates for electrons and holes are equal, then the current amplification will be

$$
G=I_{h} / I_{e}=T_{e} \tau_{h} / T_{h} \tau_{e} .
$$

If the mobilities are field independent, then $G$ would be field and geometry independent. However, since some moderately deep trapping occurs this is not to be expected.

Figure 3 shows that $G>1$ may be possible. Curve $A$ is the normal collector-current-collector voltage characteristics of the sandwich with no injection. Curve $B$ is the collector current with a constant emitter-base current of $10^{-7} \mathrm{~A}$. At zero collector voltage the collector current was $8.15 \times 10^{-10} \mathrm{~A}$. Curve $\mathrm{C}$ is the sum of the "dark" current plus the collector current at zero volts. Assuming the injected current is independent of collector voltage, the ratio of curves $B$ to $C$ would represent the amplification of injected current as a function of collector voltage. This ratio peaks at a collector voltage of $0.65 \mathrm{~V}$ with a value of 3.5. Ratios as large as 12 have been obtained. This decrease in the ratio as the field is further increased may be explained by the transit time approaching the dielectric relaxation time resulting in the onset of space-charge-limited current flow.

These results indicate that the introduction of an amorphous $p$-type material permitting the injection of minority carriers forms the basis of a new all-thin-film device, the advantages of which would be simpler fabrication and low power consumption. Also, assuming a device size similar to present integrated MOS's and geometrically extrapolating capacitances from the present device, switching speeds of $10^{-8} \mathrm{sec}$ should be obtainable. This arrangement would also be useful for many physical-property measurements such as electron transit time without the complications normally encountered

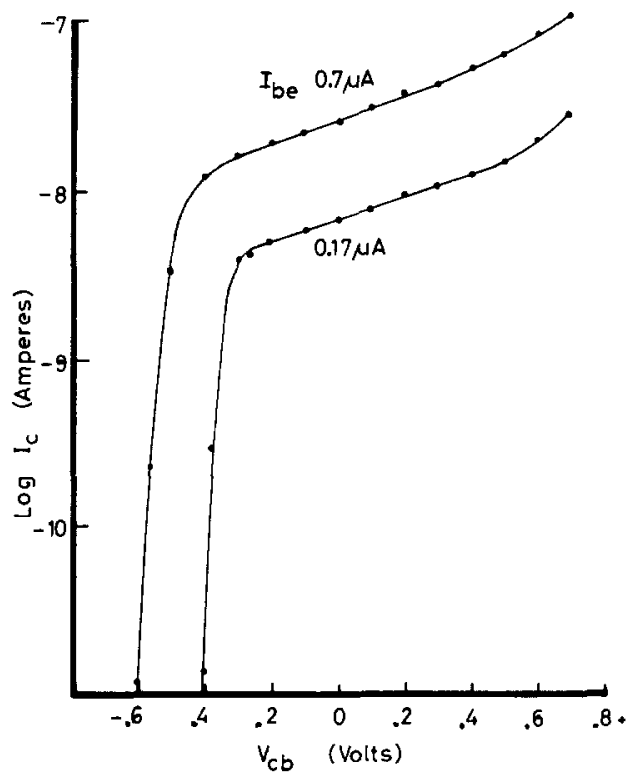

FIG. 4. Collector current as a function of collector bias polarity for two injection levels. 
in photogenerated carrier measurements. The vacuum equivalent of photoemitted electron-retarding potential measurements may also be made, as shown in Fig. 4, to study electron energy distributions and thermalization times.

*Esso Research and Engineering Company, Linden, N.J. 07036 .
JJames Franck Institute, University of Chicago, Chicago, Ill. 60637.

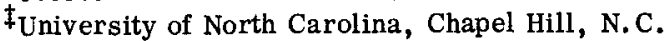

${ }^{1}$ D. G. Onn and M. Silver, Phys. Rev. 183, 295 (1969).

2J. F. Delord, Appl. Phys. Letters 11, 287 (1967).

${ }^{3}$ C.A. Mead, J. Appl. Phys. 32, 646 (1961).

${ }^{4}$ D. V. Geppert, Proc. IR E 48, 1644 (1960).

${ }^{5}$ R.N. Hall, Solid-State Electron. 3, 320 (1961).

\title{
CO Laser Action by $\mathrm{C}_{2} \mathrm{H}_{2}$ Oxidation
}

\author{
J. D. Barry and W. E. Boney \\ Laser Technology Branch, Electronic Technology Division, Air Force Avionics \\ Laboratory, Air Force Systems Command, Wright-Patterson AFB, Ohio 45433 \\ and \\ J. E. Brandelik \\ Systems Research Laboratory, 2800 Indian Ripple Road, Dayton, Ohio 45440
}

and

D. M. Mulder and J. K. Woessner

Physics Department, United States Air Force Acadomy, Colorado 80840

(Received 18 October 1971; in final form 20 December 1971)

Laser emission has been detected from $\mathrm{CO}$ molecules produced by the dic dischargeinitiated chemical oxidation of $\mathrm{C}_{2} \mathrm{H}_{2}$. The vibrational-rotational transitions were $P$ branch from $v=3: 2$ to $v=11: 10$ with $J=11-14$, nominally. The explosive property of the oxidation reaction was verified.

New chemical species are normally created in an electric discharge. The chemical reactions responsible for the formation of the new species may also lead to nonBoltzmann population distributions with potential laser action. Reactions which apparently produce such results include many oxidation schemes of organic molecules; these include the alkane-, alkene-, alkyne-, and amine-type groups. Combusion-reaction products capable of laser action from these groups include $\mathrm{CO}$ and $\mathrm{CO}_{2}$.

We have detected $\mathrm{cw}$ carbon monoxide laser emission from a directly excited liquid-nitrogen-cooled mixture of He-air $-\mathrm{C}_{2} \mathrm{H}_{2}$. The vibrationally excited $\mathrm{CO}$ molecules are produced by the discharge-initiated chemical oxidation of the acetylene.

Chemically formed $\mathrm{CO}$, with subsequent $\mathrm{cw}$ laser action, has also been observed with the oxidation of $\mathrm{CH}_{4}, \mathrm{C}_{3} \mathrm{H}_{8}{ }^{1}$ and $\mathrm{CS}_{2} \cdot{ }^{2}{ }^{3}$ Pulsed laser action has also been observed in $\mathrm{C}_{3} \mathrm{O}_{2}{ }^{4,5}$ and OCS. ${ }^{6}$ The use of $\mathrm{C}_{2} \mathrm{H}_{2}-\mathrm{O}_{2}$ to produce $\mathrm{CO}$ lasing has not been previously established to our knowledge. The primary reaction is summarized as $^{7,8}$

$$
2 \mathrm{C}_{2} \mathrm{H}_{2}+3 \mathrm{O}_{2}=4 \mathrm{CO}(v \geq 0)+2 \mathrm{H}_{2} \mathrm{O}+191 \mathrm{kcal} \text {. }
$$

Acetylene-oxidation studies ${ }^{9}$ have shown the main products to be $\mathrm{CO}, \mathrm{CO}_{2}, \mathrm{H}_{2}, \mathrm{C}_{3} \mathrm{H}_{4}$, and traces of $\mathrm{H}_{2} \mathrm{O}$. The chemiluminescence of $\mathrm{CO}$ from hydrocarbon-oxygen flames requires the formation of $\mathrm{C}_{2} \mathrm{O}$ via $\mathrm{C}_{3} \mathrm{H}_{4}$. The oxidation of $\mathrm{C}_{2} \mathrm{O}$ forms $\mathrm{CO}^{*}$ with $\mathrm{CO}(v \geq 0)$ energically possible from the reaction as well as a result of the electronic transitions. Confirmation of the reaction as leading to purely chemical laser action is at present speculative in nature. Acetylene oxidation has also been used to achieve $\mathrm{CO}_{2}$ laser emission at $10.6 \mu$, and $\mathrm{C}_{2} \mathrm{H}_{2}$ laser emission at $8 \mu$ was obtained from $\mathrm{He}-\mathrm{H}_{2}-\mathrm{C}_{2} \mathrm{H}_{2}$ mixtures. ${ }^{10,11}$

The He-air $-\mathrm{C}_{2} \mathrm{H}_{2}$ mixture was operated in an experimental apparatus similar to that previously described. The realtive gas-pressure ratio of the He-air $-\mathrm{C}_{2} \mathrm{H}_{2}$ mixture was 60-25-1, respectively, with an average tube pressure of about 3 Torr. A cw multiline power output greater than $3 \mathrm{~W}$ was observed with an electrical energy into laser radiation conversion of about $4 \%$. The laser transitions were all $P$ branch; $\mathrm{cw}$ emissions were measured in air below $5.0 \mu$ as low as $4.8939 \mu$. The spectrum extended from $v=3: 2$ to $v=11: 10$ with $J=11-14$, nominally.

Laser emission from $\mathrm{CO}$ produced by the discharge-initiated oxidation of $\mathrm{C}_{2} \mathrm{~N}_{2}$ with $\mathrm{NO}$ as the oxidizer was confirmed. ${ }^{12}$ The laser emission spectrum has not been established due to equipment limitations imposed by results of the oxidation reactions.

The oxidation of $\mathrm{C}_{2} \mathrm{H}_{2}$, as well as that of $\mathrm{C}_{2} \mathrm{~N}_{2}$, can lead to explosive results. Due to these properties, we operated the tube within a 1 -in. -thick Plexiglas enclosure situated in a well-ventilated lab. Our experience indicates that during continued discharge operation the flowing gases are required as the tube warms up from $77^{\circ} \mathrm{K}$. Catastrophic failure of the tube occurred with the gases flowing and the discharge extinguished. Apparently the hot cathode caused ignition. Explosive reactions also occurred with the use of $\mathrm{NO}-\mathrm{C}_{2} \mathrm{~N}_{2}$. These explosive reactions caused optical component damage, even though the use of the shield limited the fragmentation to the enclosed area. We wish to emphasize that great care with appropriate precautions must be exercised when operating lasers from the $\mathrm{C}_{2} \mathrm{~N}_{2}$ or $\mathrm{C}_{2} \mathrm{H}_{2}$ mixtures. 